\title{
Eleocharis wichurae (Cyperaceae): A new record for India
}

\author{
Borude, D.B. ${ }^{1}$, K.V.C. Gosavi ${ }^{2}$, C.S. Purohit ${ }^{3}$ and A.N. Chandore ${ }^{1 *}$ \\ 'Department of Botany, Abasaheb Marathe Arts and New Commerce, Science College, Rajapur, \\ Ratnagiri District. Maharashtra - 416 702, India. \\ 'Department of Botany, HPT Arts and RYK Science College, Prin. T. A. Kulkarni Vidyanagar, Nashik, \\ Maharashtra - 422 005, India. \\ ${ }^{3}$ Botanical Survey of India, Sikkim Himalayan Regional Centre (BSHC), Gangtok, Sikkim. India. \\ *E-mail: arunchandore@gmail.com
}

\begin{abstract}
Eleocharis wichurae Boeckeler (Cyperaceae) is reported for the first time from India. The present report provides a brief description, along with a photoplate and notes on distinguishing characters for its easy identification in further collections.
\end{abstract}

Keywords: Cyperaceae, Eleocharis, India, new record, Sikkim Himalaya

\section{Introduction}

The authors are engaged in the taxonomic revision of the genus Eleocharis R.Br. in India. While examining the materials of Eleocharis in BSHC (Botanical Survey of India, Sikkim Himalayan Regional Centre, Gangtok) some specimens were found identified as E. congesta D. Don. Perusal of relevant literature (Boeckeler, 1870; Dai \& Strong, 2010) and critical analysis of the glumes and nut morphology, identity of the species was revealed as E. wichurae Boeckeler. A thorough scrutiny of literature (Clarke, 1893; Cook, 1996; BSI, 2018) revealed that this species is so far not recorded from India and hence it is reported here as a new record for India.

Eleocharis wichurae Boeckeler, Linnaea 36: 448. 1870. E. petasata (Maxim.) G. Zinserl., Fl. URSS 3: 589. 1935. E. tetraquetra Nees var. wichurae (Boeckeler) Makino, Bot. Mag., Tokyo 52: 396. 1938. Scirpus petasatus Maxim., Bull. Soc. Imp. Naturalistes Moscou 54: 64. 1879.

Fig.1

Perennial herbs. Stolons short or absent. Culms greyish green, tufted, $c .30 \mathrm{~cm}$ high, slender, sharply 4-angled, smooth; sheaths 2 per culm, reddish to purplish, mouth obliquely truncate. Spikelet solitary, terminal, placed oblique at the tip of culms, brownish to pale green, ovoid to narrowly ovoid-oblong, 8-12 × 3-4 mm, distinctly wider than the culm, many-flowered, apex acute. Basal glumes 2, empty; basal-most glume amplexicaul for whole spikelet base; fertile glumes pale green medially and rust-colored striate on both sides, tightly spirally imbricate, oblong to elliptic and boat-shaped, c. $4 \times 2.3 \mathrm{~mm}$, membranous, midvein thin and obscure, margins broadly hyaline, apex obtuse-rounded. Perianth bristles 5 or 6 , unequal, rust colored, as long as or slightly longer than achene, plumose with spreading hairs; hairs $c .0 .3$ $\mathrm{mm}$ long. Style 3-lobed. Achenes pale olivaceous to brownish, obovoid to broadly obovoid, c. $1.7 \times$ $1 \mathrm{~mm}$, obtusely 3-sided, slightly compressed, both surfaces smooth, apex not constricted; persistent style base narrowly ovoid; style base as long as achene or nearly so, laterally compressed, apex acute to obtuse.

Flowering $\mathcal{E}$ fruiting: July - September.

Distribution: China, Japan, Korea, Russia (Far East, Siberia) (Dai \& Strong, 2010) and now in India.

Specimen examined: INDIA, Sikkim, Chungthang district, on the route of Chungthang-Lachen, 16.08.1989, N.R. Mandal 10470 (BSHC).

Note: E. wichurae is close to E. tetraquetra Nees, hence at times it is also treated as a variety of the latter. Clarke (1893) in Hooker's Flora of British India treated this name as a synonym under the latter. Therefore, it is obvious that the description of E. tetraquetra in the Flora of British India includes 

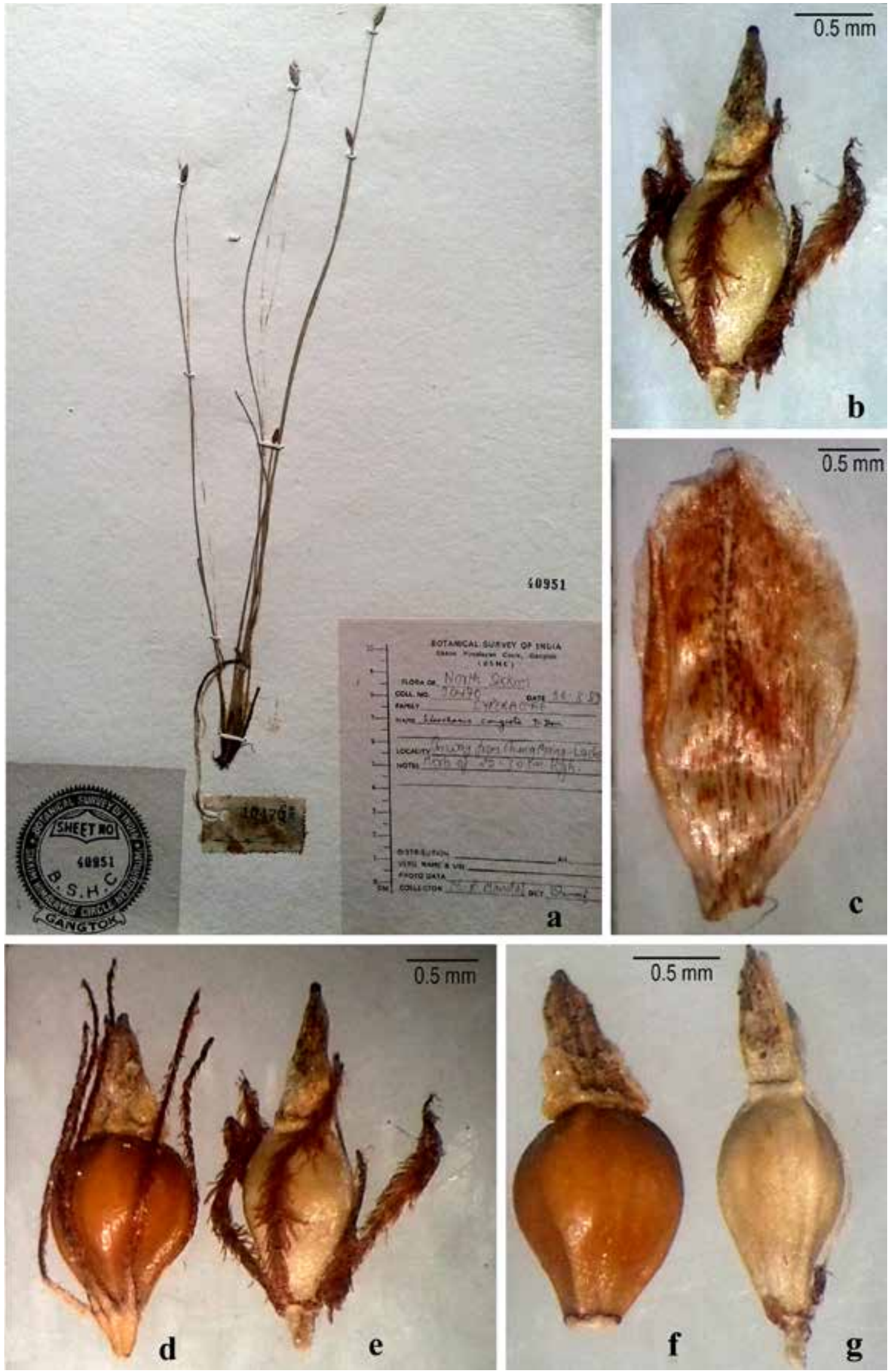

Fig. 1. Eleocharis wichurae Boeckeler: a. Herbarium specimen (N.R. Mandal 10470, BSHC); b. Achene; c. Glume; d-g. Comparison of achenes (with or without perianth bristles): $\mathbf{d} \& \mathbf{f}$. E. tetraquetra; e \& g. E. wichurae. 
the features of E. wichurae as well. However, it can be distinguished from E. tetraquetra by its larger glumes, plumose perianth bristles with spreading hairs, $1.7 \mathrm{~mm}$ long achenes (as opposed to $1.4 \mathrm{~mm}$ in E. tetraquetra) and narrowly ovoid persistent style bases.

\section{Acknowledgements}

Authors are thankful to Prof. S.R. Yadav, Department of Botany, Shivaji University, Kolhapur for encouragement; Joint Director Botanical Survey of India, Sikkim Himalayan Regional Centre (BSHC), Gangtok for necessary permission to publish herbarium images and consultation of herbarium specimens of Eleocharis. One of us (ANC) is thankful to Science and Engineering Research Board, Department of Science and Technology (SERB-DST), New Delhi for financial assistance (File No. SR/FT/LS-82/2012), under DST Fast Track Young Scientist Scheme.

\section{Literature Cited}

Boeckeler, J.O. 1870. Heleocharis wichurae. Linnaea 36: 448.

BSI, 2018. Checklist of Plants of India. Facilitated by the Botanical Survey of India, Kolkata. Available on http://efloraindia.nic.in/ efloraindia/speciesList_PCL.action?result T ype=genusWise\&parent_Id=2891\&parent_ Name=eleocharis (accessed: 31.05.2018).
Clarke, C.B. 1893. Cyperaceae. In: Hooker, J.D. (Ed.), Flora of British India. Vol. 6. L. Reeve \& Co. Ltd., London. pp. 625-630.

Cook, C.D.K. 1996. Aquatic and Wetland Plants of India. Oxford University Press, London. pp. 126-131.

Dai, L.K. \& M.T. Strong 2010. Eleocharis. in: Wu, Z.Y., Raven, P.H. \& D.Y. Hong (Eds.), Flora of China. Vol. 23. Science Press, Beijing and Missouri Botanical Garden Press, St. Louis. pp. 188-200.

\section{Received: 05.12.2016}

Revised and Accepted: 10.06.2018 